\title{
Effect of hexamethylenetetramine on surface smoothness of electroplated copper coating
}

\author{
Xiang Jing ${ }^{1,2, a^{*}}$, Sheng Wenjing ${ }^{1}$, Li Jie ${ }^{1}$, Zeng Chong ${ }^{1,2}$, Xu Yonggang ${ }^{1}$, Yang Wenyao ${ }^{1}$, and Wang Jingjie ${ }^{1}$ \\ ${ }^{1}$ Chongqing Engineering Research Center of New Energy Storage Devices and Applications, Chongqing University of Arts and Sciences \\ Chongqing, 402160, China \\ ${ }^{2}$ Postdoctoral Research Station, China Silian Instrument Group Co., Ltd, 400707, China
}

\begin{abstract}
In this paper, hexamethyltetramine is introduced into the electroplating bath to improve the surface morphology of electrodeposited copper. The cyclic voltammetry $(\mathrm{CV})$ and dynamic polarization curves are used to study the effect of $\mathrm{Cu}(\mathrm{I})$ and hexamethyltetramine on the electrochemical behaviors of electroplating solution. After implementing the electrodeposited copper experiment, scanning electron microscope (SEM) and X-ray diffraction (XRD) are used to explore the influence of $\mathrm{Cu}(\mathrm{I})$ and hexamethyltetramine on the Surface morphology and crystal plane orientation of the electrodeposited copper. The results show that $5 \mathrm{ppm}$ hexamethyltetramine and $7.5 \mathrm{ppm}$ hexamethyltetramine can solve the problem of the loose and uneven surface of the electroplated copper layer caused by $\mathrm{Cu}(\mathrm{I})$.
\end{abstract}

\section{Introduction}

Copper interconnect structure of package substrate is important for enabling signal transmission between the chip and the printed circuit board (PCB). Surface evenness of the copper layer is importance for achieving low transmission loss at high frequency for high speed signals [1-3]. Now, copper electrodeposition technology of copper interconnected structure is based on the synergistic mechanism of organic additives to achieve selective copper electrodeposition in the pattern space in the acid copper electroplating system [4-7]. For copper electrodeposition, the organic additives are mainly divided into three types, including organic accelerators, inhibitors and levelers [8-10]. According to competitive adsorption and synergy of the three additives in cathode surface, interconnecting microcircuits and microvias of PEB with different shapes and sizes can be obtained.

Notably, organic accelerators of copper electrodeposition are very important for interconnected structure to product a smooth and bright copper surface. Moreover, the common organic accelerators are mainly bis-3-sulfopropyl-disulfide(SPS) and 3-mercapto-1propanesulfonate(MPS) in the acid copper electroplating system [11-13]. Hayashi used rotating ring-disk electrode to monitor $\mathrm{Cu}(\mathrm{I})$ to prove that the $\mathrm{Cu}(\mathrm{I})$ produced at the anode and cathode is increased by 5000 times in the electroplating solution system containing additives [14]. $\mathrm{Cu}(\mathrm{I})$ can react with SPS to produce $\mathrm{Cu}(\mathrm{I}) / \mathrm{SPS}$ [15]. However, Hayashi proposed that $\mathrm{Cu}(\mathrm{I})$ can react with SPS to generate $\mathrm{Cu}(\mathrm{I})-\mathrm{MPS}[16]$.

During the electrodeposition process of the interconnected copper structure, the method of continuously introducing air is usually used to oxidize the free $\mathrm{Cu}(\mathrm{I})$ in the electroplating solution to $\mathrm{Cu}(\mathrm{II})$ to avoid the influence of the $\mathrm{Cu}(\mathrm{I})$ on the electrodeposited copper.In particular, it is still unclear how the large amount of $\mathrm{Cu}(\mathrm{I})$ generated at the anode in the plating solution affects the electrodeposited copper layer.

In this article, the hexamethyltetramine(HT), as a new addtive of copper electrodeposition, is introduced into the electroplating solution to improve the surface morphology of electrodeposited copper. In addition, the electrochemical analysis methods and surface detection technologies are used to study $\mathrm{H}$ ) suppress the roughness and uneven surface of the electroplated copper layer caused by $\mathrm{Cu}(\mathrm{I})$.

\section{Methods and Materials}

Virgin Make-up Solution (VMS) was composed of 0.6 M $\mathrm{CuSO}_{4} \cdot 5 \mathrm{H}_{2} \mathrm{O}, 1.85 \mathrm{M} \mathrm{H}_{2} \mathrm{SO}_{4}, 2 \mathrm{mM} \mathrm{Cl}^{-}$in distilled water (DI water). The cuprous oxide was added to the electroplating solutions as the source of $\mathrm{Cu}(\mathrm{I})$. Table 1 is the composition of the additive of the electrodeposition system. The conventional electrolyte system (CES) is composed of VMS, $200 \mathrm{mg} / \mathrm{L} \mathrm{PEG}$ and $1 \mathrm{mg} / \mathrm{L}$ SPS. PCB fragments of $15 \mathrm{~cm} \times 5 \mathrm{~cm}$ are produced for plating samples.

The plating test boards were double-sided copper clad laminate. The boards were pre-processed by degreasing, micro-etching and pre-dipping to clean and wet copper surfaces of boards before copper electrodeposition. Subsequently, electrodeposition copper experiments were implemented in Haring cell at the current density of 2 $\mathrm{A} / \mathrm{dm}^{2}$ for $1200 \mathrm{~s}$. The temperature of electrodeposition was $298 \mathrm{~K}$. After electrodepositing copper, DI water was used to clean the copper layer surface electroplating

\footnotetext{
a Corresponding author: xiangjing@cqwu.edu.cn
} 
solution, and the dryer is applied to dry the copper layer surface.

Electrochemical behavior of accelerators was performed by electrochemical work station (CHI760E) with three electrodes at $298 \mathrm{~K}$. A platinum rotating disk electrode (Pt-RDE) with a diameter of $5 \mathrm{~mm}$ was used as working electrode (WE). The speed of RDE was 1000 rpm. A copper bar with a diameter of $8 \mathrm{~mm}$ was as the counter electrode (CE). The reference electrode (RE) was saturated mercurous sulfate electrode (SMSE). Characterizations of plating copper surface were analyzed by SEM (JEOL, JSM-6060), camera and XRD (MXP3, MAC SCIENCE).

Table1. The composition of the additive of the electrodeposition system.

\begin{tabular}{|c|c|c|c|c|}
\hline Item & PEG & SPS & Cu(I) & HT \\
\hline $\mathrm{a}$ & $200 \mathrm{ppm}$ & $1 \mathrm{ppm}$ & 0 & 0 \\
\hline $\mathrm{b}$ & $200 \mathrm{ppm}$ & $1 \mathrm{ppm}$ & $20 \mathrm{ppm}$ & 0 \\
\hline $\mathrm{c}$ & $200 \mathrm{ppm}$ & $1 \mathrm{ppm}$ & $20 \mathrm{ppm}$ & $2.5 \mathrm{ppm}$ \\
\hline $\mathrm{d}$ & $200 \mathrm{ppm}$ & $1 \mathrm{ppm}$ & $20 \mathrm{ppm}$ & $5 \mathrm{ppm}$ \\
\hline $\mathrm{e}$ & $200 \mathrm{ppm}$ & $1 \mathrm{ppm}$ & $20 \mathrm{ppm}$ & $7.5 \mathrm{ppm}$ \\
\hline
\end{tabular}

\section{Results and discussion}

\subsection{Electrochemical analysis}

Figure 1 shows the $\mathrm{CV}$ test results of five different electroplating systems. The potential step length of the $\mathrm{CV}$ test is $0.05 \mathrm{mV}$, the scanning range starts from $-0.4 \mathrm{~V}$ to $-0.685 \mathrm{~V}$, and the scanning speed is $0.5 \mathrm{~m} / \mathrm{s}$. Figure 2 is the stripping peak areas obtained by the $\mathrm{CV}$ test of the electrodeposition system with five different HT concentrations. Generally, the larger the stripping peak area means the faster the electrodeposition rate of the electrodeposition system. Obviously, the addition of $\mathrm{Cu}(\mathrm{I})$ in electroplating solution leads to an increase in the rate of copper electrodeposition. The reason is that $\mathrm{Cu}(\mathrm{I})$ requires only one electron to generate copper compared with $\mathrm{Cu}(\mathrm{II})$. On the other hand, the $\mathrm{Cu}(\mathrm{I})$ can react with SPS to form MPS, which is the stronger accelerator than SPS. Subsequently, the addition of $2.5 \mathrm{ppm}$ HT in electroplating solution also causes an increase in the value and area of stripping peak of the electrodeposited copper. Namely, HT can promote copper electrodeposition. moreover, both $\mathrm{Cu}(\mathrm{I})$ and HT lead to a positive shift in the position of the copper stripping peak of the electroplating solution system to demonstrate that $\mathrm{Cu}(\mathrm{I})$ and HT enhance the polarization on the surface of the electrodeposited cathode. It is worth noting that there is no significant difference in the effect of HT on the peak of the CV curve at 5 ppm HT and 7.5 ppm HT in Figure 2. It can be considered that the concentration of HT reaches saturation at $5 \mathrm{ppm}$ for CES with 20ppm $\mathrm{Cu}(\mathrm{I})$. In a word, the $\mathrm{Cu}(\mathrm{I})$ and $\mathrm{HT}$ can accelerate the rate of copper electrodeposition and enhance the polarization of the cathode surface.

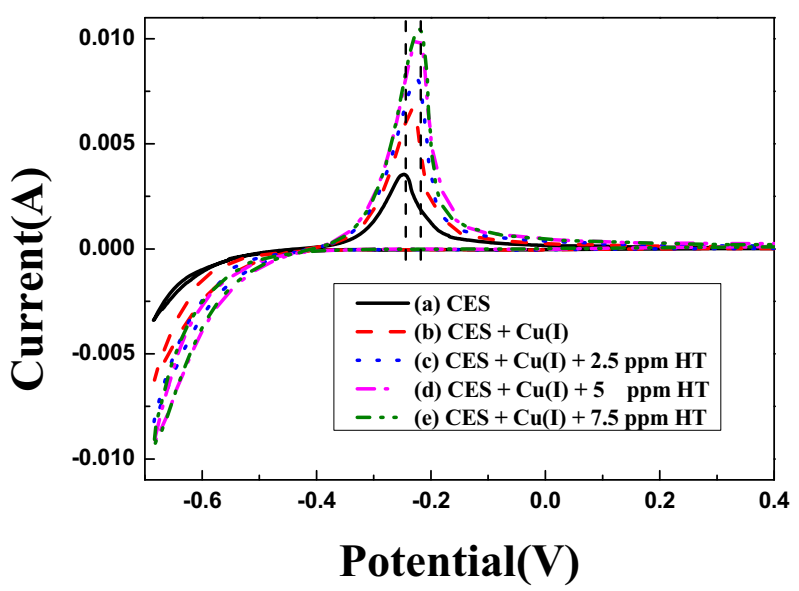

Figure 1. CV test results of five different electroplating solutions.

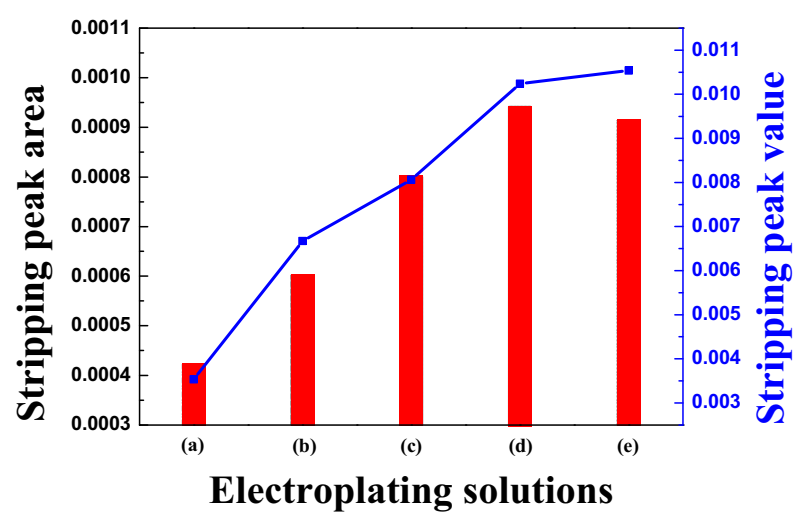

Figure 2. Stripping peak of CV curves in the electroplating solutions with five different electroplating solutions: (a) CES, (b) $\mathrm{CES}+\mathrm{Cu}(\mathrm{I}),(\mathrm{c}) \mathrm{CES}+\mathrm{Cu}(\mathrm{I})+2.5 \mathrm{ppm} \mathrm{HT}$, (d) $\mathrm{CES}+$ $\mathrm{Cu}(\mathrm{I})+5 \mathrm{ppm} \mathrm{HT}$ and (e) $\mathrm{CES}+\mathrm{Cu}(\mathrm{I})+7.5 \mathrm{ppm} \mathrm{HT}$.

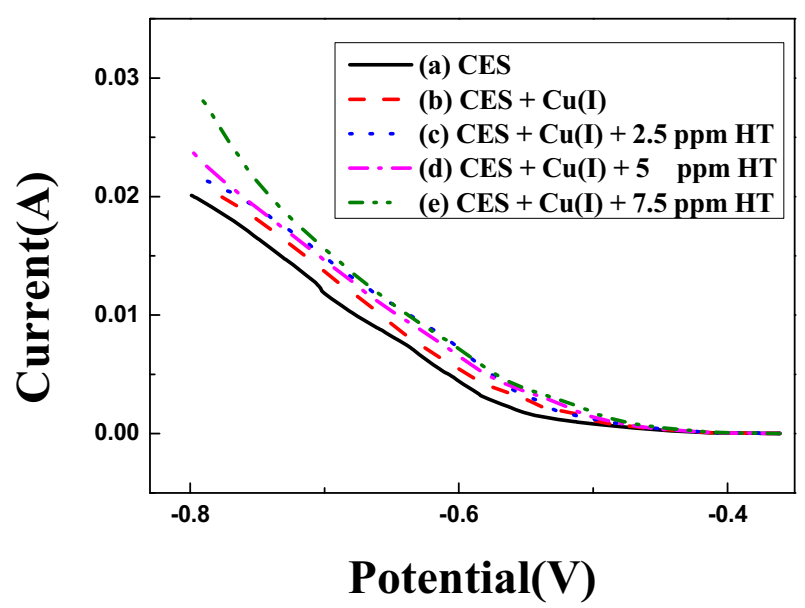

Figure 3. Dynamic polarization curves of five different electroplating solutions.

Dynamic polarization curves of five different electroplating solutions are shown in Figure 3. The potential step length of the polarization curve test is 0.5 $\mathrm{mV}$, the scanning range starts from $-0.38 \mathrm{~V}$ to $-0.8 \mathrm{~V}$, and the scanning speed is $0.5 \mathrm{~m} / \mathrm{s}$. Obviously, with the negative shift of the cathode potential from $-0.4 \mathrm{~V}$ to $0.8 \mathrm{~V}$, the cathode current density becomes larger and the electrodepositing copper rate increases. At different 
potentials, the cathode current density in the CES electroplating solution is the smallest to prove that the rate of electrodepositing copper is the smallest. On the contrary, the cathode current density in the electroplating solution containing HT is the largest to indicate that the rate of electrodepositing copper is the largest. It is worth noting that when the potential exceeds $0.7 \mathrm{~V}$, the increase in potential causes the current rate of change of the electroplating solution containing $7.5 \mathrm{ppm}$ to become largest. Namely, HT has an enhanced effect on the promotion of electrodeposited copper at a high potential. However, for other electroplating solution systems, the potential has a linear correlation with the current and the increase in potential can not cause a change in the overall impedance of the system. Under the same cathodic current, both $\mathrm{Cu}(\mathrm{I})$ and $\mathrm{HT}$ can make the copper electrodeposition potential move forward and enhance the polarization of the electroplating solution, which further reduces the electrodeposition potential and accelerates the electrodeposition of copper. Obviously, the results of the $\mathrm{CV}$ test and the polarization curve test are consistent. In short, it can be further proved that $\mathrm{Cu}(\mathrm{I})$ and $\mathrm{HT}$ can accelerate copper electrodeposition process by the polarization curve results.

\subsection{Physical characterization}

The images of SEM of electrodeposited copper for five different electroplating solutions are shown in Figure 4. The surface of the copper layer obtained by electrodeposition in CES is smooth and dense. Obviously, after adding cuprous ions in CES, more cavities appear on the surface of electrodeposited copper to making the surface uneven and loose. $\mathrm{Cu}(\mathrm{I})$ has a strong coordination ability with organics. On the other hand, $\mathrm{Cu}(\mathrm{I})$ is unstable and easily oxidized to $\mathrm{Cu}(\mathrm{II})$. It can be speculated that the $\mathrm{Cu}(\mathrm{I})$ can complex with organic additives in the electroplating solution system and change the adsorption on the cathode surface. In addition, the $\mathrm{Cu}(\mathrm{I})$ can react with SPS and affect the acceleration performance of SPS. It can be seen that $\mathrm{Cu}(\mathrm{I})$ can accelerate the speed of copper electrodeposition, but has a very serious destructive effect on the surface morphology of the electrodeposited copper layer. It is worth noting that the addition of HT in CES with $\mathrm{Cu}(\mathrm{I})$ significantly improves the microscopic surface morphology of the electrodeposited copper layer. Therefore, HT can increase the electrodeposited copper and improve the surface defects of the electrodeposited copper layer caused by $\mathrm{Cu}(\mathrm{I})$. moreover, the morphology of the electrodeposited copper layer surface obtained in the electroplating solution with HT concentrations of 5 ppm and $7.5 \mathrm{ppm}$ is basically the same as that obtained in CES with $\mathrm{Cu}(\mathrm{I})$. In a word, HT can solve the problem of surface defects of the electrodeposited copper layer caused by $\mathrm{Cu}(\mathrm{I})$.

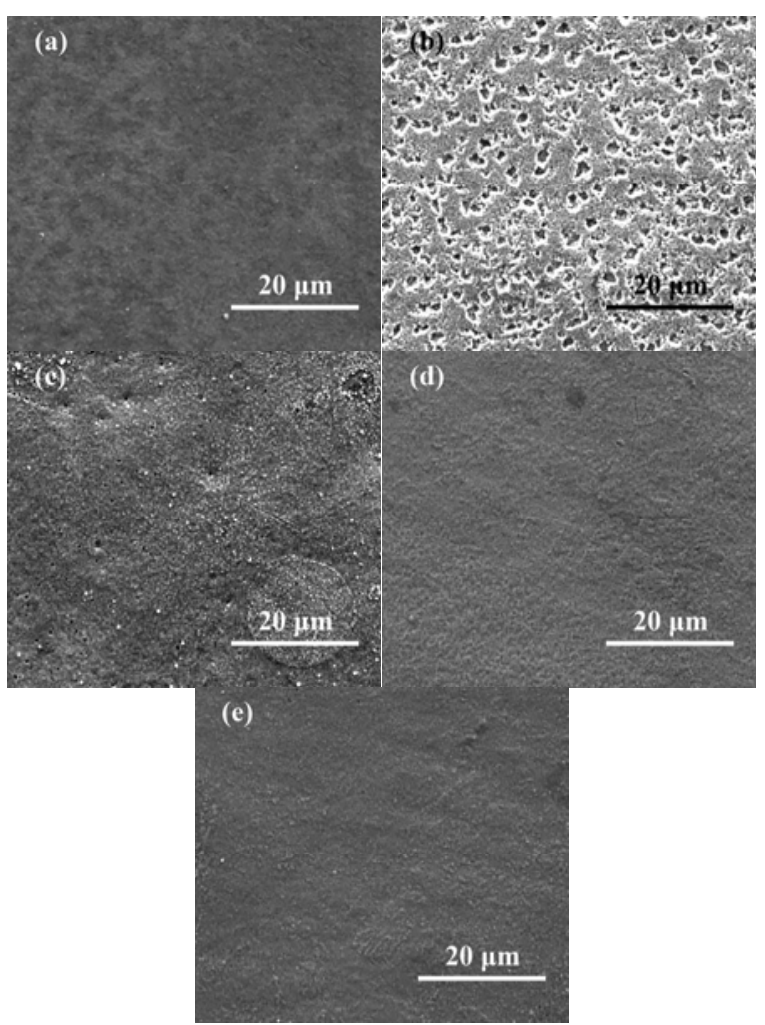

Figure 4. The images of SEM of electrodeposited copper for five different electroplating solutions: (a) CES, (b) CES + $\mathrm{Cu}(\mathrm{I}),(\mathrm{c}) \mathrm{CES}+\mathrm{Cu}(\mathrm{I})+2.5 \mathrm{ppm} \mathrm{HT},(\mathrm{d}) \mathrm{CES}+\mathrm{Cu}(\mathrm{I})+5$ ppm HT and (e) CES $+\mathrm{Cu}(\mathrm{I})+7.5$ ppm HT.

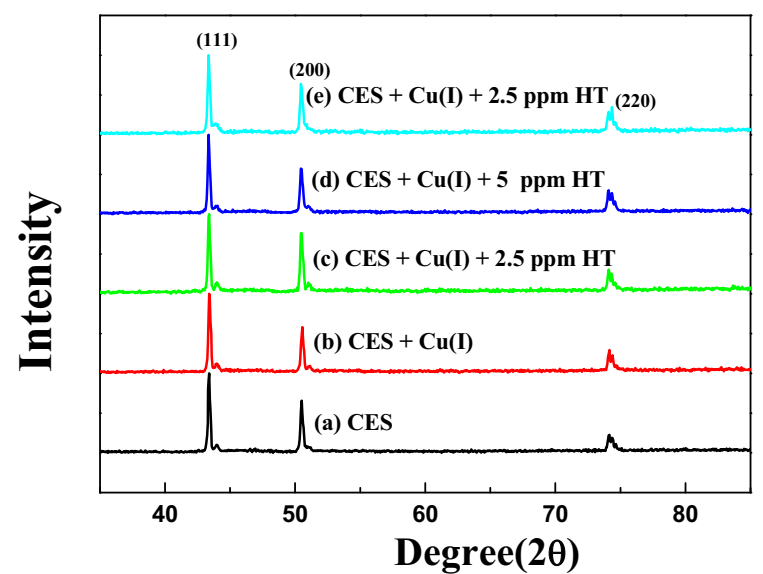

Figure 5. XRD results of electrodeposited copper for five different electroplating solutions.

XRD results of electrodeposited copper for five different electroplating solutions is shown in Figure 5. It can be observed that the grain growth direction of the copper plating layer deposited by the five electroplating systems is mainly the (111), (200) and (220) crystal planes of copper. In general, the intensity of crystal plane (111) is the highest and crystal plane (220) is the lowest in Figure 6. Comparing the crystal planes of the copper layer obtained by different electroplating solutions, the addition of $\mathrm{Cu}(\mathrm{I})$ has no significant effect on the proportion of (111) crystal planes, but it can cause the proportion of (220) crystal planes to decrease and increase the proportion of (200) crystal planes. Namely, $\mathrm{Cu}(\mathrm{I})$ mainly promotes the growth of the (200) crystal plane of copper and inhibits the growth of the (220) crystal plane of copper. The low 
concentration of HT causes the (111) and (200) crystal planes to decrease, but causes the (220) crystal planes to increase. The reason is that there is an intermediate reaction process between $\mathrm{HT}$ and $\mathrm{Cu}(\mathrm{I})$ in the electroplating solution system to cause the change in the selection of the crystal face of the electrodeposited copper. However, high concentrations of HT promote the growth of (200) and (220) crystal planes and inhibit the growth of (111) crystal planes. And the increase of (200) and (220) crystal plane orientation contributes to the corrosion resistance of the copper layer surface. In summary, the HT can promote the selection of the copper crystal plane (200) and (220) orientation in the electrodeposited copper. Combining the SEM and XRD results, it was found that HT can significantly improve the surface morphology of electrodeposited copper.

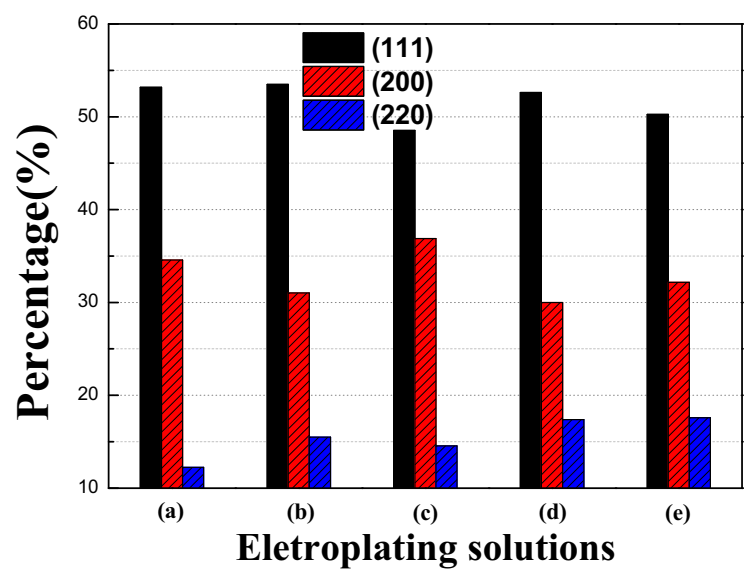

Figure 6. Crystal plane of electrodeposited copper for five different electroplating solutions: (a) CES, (b) CES + $\mathrm{Cu}(\mathrm{I}),(\mathrm{c}) \mathrm{CES}+\mathrm{Cu}(\mathrm{I})+2.5 \mathrm{ppm} \mathrm{HT}$, (d) $\mathrm{CES}+\mathrm{Cu}(\mathrm{I})+5$ ppm HT and (e) CES $+\mathrm{Cu}(\mathrm{I})+7.5 \mathrm{ppm}$ HT .

\section{Conclusions}

Hexamethyltetramine is introduced into the electroplating bath to improve the surface morphology of electrodeposited copper. The results of $\mathrm{CV}$ and dynamic polarization curves prove that $\mathrm{Cu}(\mathrm{I})$ and hexamethyltetramine can accelerate the rate of copper electrodeposition. SEM results show that $\mathrm{Cu}(\mathrm{I})$ can lead to the formation of voids on the surface of the electrodeposited copper. Especially, the addition of hexamethyltetramine can significantly improve the surface defects of the electrodeposited copper layer. In addition, hexamethyltetramine can also promote the selection of the copper crystal plane (200) and (220) orientation in the electrodeposited copper. The introduction of hexamethyltetramine in electroplating solution can enhance the polarization of the electroplating solution, promote copper electrodeposition and solve the surface defects of the copper layer caused by $\mathrm{Cu}(\mathrm{I})$ and obtains a more corrosive copper layer. In short, HT is an additive that has a certain effect on electrodeposited copper, and its mechanism of action will be further studied.

\section{Acknowledgment}

The authors gratefully acknowledge the support of the Scientific Research Fund of Chongqing Municipal Education Commission (No. KJQN201901316, No. KJQN201901304, KJQN202001322 and KJQN202001315), Natural Science Foundation of Chongqing (No. cstc2019jcyj-msxmX0824), Foundation for High-level Talents of Chongqing University of Art and Sciences (No. R2019FDQ12, NO.2017RDQ28, R2020SDQ02, R2019FDQ13), College Student Innovation and Entrepreneurship Training Program (S202010642023 and S202010642024).

\section{References}

1. Y. Chen, Y. Chen, J. Wang, K. Zhu, L. Jia, S. Wang, W. He, Q. Chen, H. Miao, and J. Zhou, Composites Part B: Engineering, 158 400-405 (2019).

2. D. Straubinger, A. Géczy, A. Sipos, A. Kiss, D. Gyarmati, O. Krammer, D. Rigler, D. Bušek, and G. Harsanyi, Circuit World, 45 (2019).

3. H. Zhou, X. Gao, J. Lai, and W. Hu, IEEE Access, PP (2018).

4. C. Wang, J. Zhang, P. Yang, and M. An, Electrochimica Acta, 92 356-364 (2013).

5. L. Zheng, W. he, K. Zhu, C. Wang, S. Wang, Y. Hong, Y. Chen, G. Zhou, H. Miao, and J. Zhou, Electrochimica Acta, 283 (2018).

6. T. Chang, Y. Jin, L. Wen, C. Zhang, C. Leygraf, I. Wallinder, and J. Zhang, Electrochimica Acta, 211 (2016).

7. J. Li, G. Zhou, Y. Hong, C. Wang, W. He, S. Wang, Y. Chen, Z. Wen, and Q. Wang, ACS Omega, 5 (10), 4868-4874 (2020).

8. J. Luo, Z. Li, M. Shi, J. Chen, Z. Hao, and J. He, Journal of The Electrochemical Society, 166 D104D112 (2019).

9. C. Liao, S. Zhang, S. Chen, Y. Qiang, G. Liu, M. Tang, B. Tan, D. Fu, and Y. Xu, Journal of Electroanalytical Chemistry, 827 (2018).

10. Z. Lai, C. Wang, Y. Huang, Y. Chen, S. Wang, Y. Hong, G. Zhou, W. he, X. Su, Y. Sun, Y. Tao, and X. Lu, Materials Today Communications, 24100973 (2020).

11. H. Shen, H. Kim, M. Sung, T. Lim, and J. Kim, Journal of Electroanalytical Chemistry, 816 (2018).

12. M. Kunimoto, F. Yamaguchi, M. Yanagisawa, and T. Homma, Journal of The Electrochemical Society, 166 D212-D217 (2019).

13. C.-C. Lin, C.-C. Hu, Y.-T. Lu, and R.-H. Guo, Electrochemistry Communications, 91 75-78 (2018).

14. T. Hayashi, K. Kondo, T. Saito, N. Okamoto, M. Yokoi, M. Takeuchi, M. Bunya, M. Marunaka, and T. Tsuchiya, Journal of The Electrochemical Society, 160 (6), D256-D259 (2013).

15. T. Okubo, K. Watanabe, and K. Kondo, Journal of The Electrochemical Society, 154 (3), C181 (2007). 
16. T. Hayashi, S. Matsuura, K. Kondo, K. Kataoka, K. Nishimura, M. Yokoi, T. Saito, and N. Okamoto, Journal of the Electrochemical Society, 162 (6), D199-D203 (2015). 